\title{
La revitalización de la historiografía política chilena
}

\author{
José Ignacio Ponce López \\ Universidad de Valparaíso, Valparaíso, Chile. \\ Email: jose.ponce.lopez@gmail.com
}

\section{Aníbal Pérez Contreras}

Universidad de Santiago, Santiago, Chile.

Email: anibal.perez@usach.cl

\begin{abstract}
Resumen: ${ }^{1}$ Abordamos el proceso de revitalización experimentado por la historiografía política crítica chilena. Para ello, analizamos sus principales fuentes de inspiración: a) el contexto histórico político nacional; b) la crítica de la Nueva Historia Social; c) la aparición de escuelas historiográficas europeas sobre temas afines. Postulamos que: a partir de esta multidimensional relación resultó una particular síntesis crítica, revisionista y renovada para abordar el devenir histórico político reciente de Chile, lo que reposicionó los estudios sobre lo político hacia inicios del siglo XXI, llenando paulatinamente un vacío historiográfico dejado por las diversas variantes disciplinarias del siglo pasado. Al andar desarrolló sus propias características investigativas, que algunos historiadores acompañaron con novedosos esfuerzos teóricos para fundamentar epistemológicamente su quehacer. Entre ellos ha destacado lo planteado desde distintas ópticas por Cristina Moyano, Luis Corvalán y Juan Carlos Gómez. La metodología usada es principalmente cualitativa, incluyendo técnicas de historia oral en los casos pertinentes.
\end{abstract}

Palabras clave: Historia Política, Nueva Historia Social, Crítica, Revitalización, Historia Reciente.

\section{The revitalization of chilean political historiography}

\begin{abstract}
We approach the revitalization that has experienced the chilean critical and political historiography. To do this, we analyze their main sources of inspiration: a) the historical and political chilean context, b) the review of the «New Social History»; c) the emergence of european historiographical schools of related topics. We postulate that: from this multidimensional relationship resulted a particularly critical synthesis, «revisionist» and renewed to approach the recent historical and political Chilean processes, which repositioned the political studies at the beginning of XXI century, filling a historiographical void left by the different disciplinary variants of the last century. In doing this it developed its own investigative characteristics, that some historians accompanied with novel theoretical efforts to substantiate epistemologically their work. Among them have highlighted the issues raised from different viewpoints of Cristina Moyano, Luis Corvalán and Juan Carlos Gómez. The methodology used is primarily qualitative, including oral history techniques where appropriate.
\end{abstract}

Recent History.

Key words: Political History, New Social History, Critical, Revitalization, 


\section{A revitalização da historiografia política chilena}

Resumo: Abordamos o processo de revitalização experimentada pela historiografia política crítica chilena. Analisamos as principais fontes de inspiração : a) o contexto histórico político nacional b ) a crítica da «Nova História Social», c) o surgimento de escolas historiográficas europeias sobre temas relacionados. Postulamos que: a partir desta relação multidimensional foi uma síntese crítica particular, «revisionista» e renovada para abordar o recente desenvolvimento político histórico do Chile, que reposicionou os estudos políticos no início do século, gradualmente enchendo um «vazio " historiográfica deixado por essas variantes disciplinares do século passado. Este processo desenvolveu suas próprias características de pesquisa, que alguns historiadores acompanharam com novos esforços teóricos para justificar epistemologicamente seu trabalho. Destacarmos as questões levantadas de diferentes ângulos por Cristina Moyano, Luis Corvalan e Juan Carlos Gomez . A metodologia é essencialmente qualitativa, incluindo as técnicas de história oral se for caso disso .

Palavras-chave: História Política, História Social New Review, Revitalização, a história recente.

$$
* * *
$$

\section{Introducción}

En el siguiente artículo analizaremos la revitalización de los estudios sobre lo político en la historiografía chilena, realizados en las últimas dos décadas. La pregunta que buscamos responder versa sobre las características históricas que explicarían dicho proceso, junto con los planteamientos teóricos, las principales interrogantes y objetos de estudio que se han ido desarrollando en el seno de la reformulación de la historiografía política chilena.

Como respuesta sugeriremos que el replanteamiento de lo político se comenzó a dar en un contexto teórico signado por la serie de cuestionamientos a los paradigmas epistemológicos y políticos predominantes durante el siglo XX. La llamada crisis de los paradigmas y de los metarrelatos que hegemonizaron el quehacer académico y político mundial (López 2000: 94-97), se cruzó, en el plano nacional, con un marco histórico caracterizado por los Gobiernos Posdictatoriales de la Concertación de Partidos por la Democracia. La carencia explicativa desde una perspectiva histórica y crítica de los fenómenos del pasado reciente criollo, incentivó a un grupo heterogéneo de cientistas sociales a preguntarse sobre lo político, que hacia inicios del siglo XXI, comenzaron a copar gradual y paulatinamente una suerte de vacío historiográfico dejado por las diversas corrientes historiográficas del siglo pasado.

Ahora bien, esta historiografía política criolla revitalizada, no desechó todo el trabajo de la historiografía crítica anterior a ella. Por el contrario, tomó elementos importantes de la llamada Nueva Historia Social chilena. De allí que recogiera la doble crítica propugnada por ésta: por una par- 
te, el rechazo a las tesis clásicas de los historiadores decimonónicos -representantes del modelo académico tradicional (Fontana: 2004)-; y, por otra, el cuestionamiento a las ideas principales planteadas por los llamados historiadores marxistas clásicos chilenos ${ }^{2}$.

Los impulsores de la Nueva Historia Social -marcados por la derrota política que significó el Golpe de Estado de 1973- cuestionaron las premisas que sostuvieron al movimiento político histórico que llevó a Allende a la Moneda. Buscando respuestas al Golpe, se enfocaron principalmente en los orígenes de la composición del movimiento popular -a fines del siglo XIX y comienzos del XX- para desde ahí, construir una crítica al desarrollo histórico de las relaciones de explotación y dominación en la historia de nuestro país.

Esta óptica de largo plazo para explicar la coyuntura de 1973 que, como veremos, será criticada por los historiadores políticos del siglo XXI, no impidió que éstos rescataran el ejercicio profundamente crítico e interdisciplinario que habían buscado los nuevos historiadores sociales, a fin de tensionar los planteamientos de la historiografía tradicional y conservadora chilena ${ }^{3}$.

Con todo, los historiadores políticos del siglo XXI han sumado otro rasgo particular, además de su dimensión analítica de la sociedad (lo político) y su ejercicio crítico: la llamada historia reciente. La aparición con fuerza de los historiadores políticos críticos chilenos se dio a fines del siglo XX y comienzo del siglo XXI, bajo la llamada transición a la democracia durante la década de 1990 -en la cual se gestaron una serie de novedosos fenómenos políticos, económicos y sociales para el país-, contexto propicio para que surgieran interesantes preguntas para una nueva gama de historiadores e historiadoras, los cuales -rescatando algunas premisas de los nuevos historiadores sociales-, terminaron cuestionando la realidad social de su presente, pero desde el pasado reciente. Esto último los llevó a preguntarse -preferentemente- sobre los fenómenos acaecidos bajo el Gobierno de la Unidad Popular, la Dictadura Militar y los Gobiernos Concertacionistas.

Las interrogantes preliminares que han tenido estos historiadores políticos, han sido cobijadas en apuestas teóricas dadas más allá de las fronteras nacionales. En efecto, a nivel mundial tras la crisis disciplinaria de los años 1970 y 1980 (Moyano 2011a: 232) se ha ido gestando una recomposición teórica en las diversas ciencias sociales, que en el caso de la historiografía a escala planetaria, ayudó al resurgimiento de la historia política. Es así que, desde Europa, esta última haya logrado renovarse metodológica y temáticamente, pasando de ser un campo menoscabado y marginado durante el siglo XX, a uno protagónico y central en la actualidad. En este caso han sido los sujetos y las subjetividades, junto con perspectivas constructivistas y culturales, las que han destacado y posibilitado la aparición de dos importantes corrientes en Francia: la llamada Nueva Historia Política encabezada por René Remond y la Historia Conceptual de 
lo Político donde destaca el trabajo realizado por Pierre Rossanvallon. A esto pueden agregarse también los trabajos de Reinhart Koselleck en el caso alemán, junto con Quentin Skinner para el fenómeno inglés. Como veremos, sus aportes han sido otra fuente de inspiración para algunas y algunos impulsores de la historiografía política crítica chilena.

Si bien el aporte de las corrientes intelectuales mundiales ha sido relevante, las hipótesis planteadas por las y los historiadores políticos nacionales, no tuvieron como rasgo común un paradigma teórico único, sino más bien un ejercicio crítico y revisionista de las tesis afirmadas por la historiografía tradicional. Esto promovió lecturas más bien heterodoxas y complejas sobre la realidad histórica social. De allí que esta reformulación de la historia política reciente del país, lejos de cristalizar en una escuela historiográfica o articularse bajo una interpretación histórica única, se ha nutrido de las distintas vertientes que hemos ido enunciando.

La diversidad y complejidad que se puede evidenciar, ha provocado la coexistencia de distintas posturas sobre el quehacer académico entre los historiadores de lo político. Esto último, permite apreciar perspectivas que enfatizan la aplicación a nivel nacional de los avances internacionales de la Nueva Historia Política, la Historia Conceptual de lo político y la Historia del Tiempo Presente, donde Cristina Moyano ha realizado el mayor esfuerzo teórico por sintetizar estos trabajos. Otros historiadores, privilegian una visión materialista, tal como propone Luis Corvalán Marquéz, que en el caso de Juan Carlos Gómez Leyton se ha profundizado en un sentido interdisciplinario, proponiendo una Ciencia Política Histórica.

Para argumentar estas afirmaciones, analizaremos el contexto histórico e intelectual en el cual se gesta y desarrolla esta revitalización de la historiografía política crítica. Posteriormente, veremos los aportes de la Nueva Historia Social para este proceso. Continuaremos caracterizando el proceso de revitalización de la historiografía política crítica sobre el pasado reciente chileno. Después profundizaremos, en base a fuentes bibliográficas y orales, en las apuestas teóricas de los historiadores políticos chilenos del siglo XXI, para finalizar con algunas conclusiones sobre lo analizado.

\section{El contexto histórico, político e intelectual previo a la revitalización de la historiografía política en Chile}

En las últimas tres décadas, a nivel europeo (Cruz 1993; Sirinelli 1993), americano (Palacios 2007) y nacional (Moyano, 2011a; Monsalve 2011) la historia política se ha reposicionado como un importante campo de estudio. Para entender el caso chileno, creemos que es importante seguir la afirmación realizada por Altamirano quien, pensando sobre Latinoamérica, sostiene: el renacimiento del interés en la historia política en América no podría disociarse, por cierto, de las desventuras políticas del subcontinente (2005: 5). En este sentido, las preguntas sobre el pasado reciente se desa- 
rrollan en un contexto de derrotas de los procesos y movimientos revolucionarios de los años '70 y '80, las que se materializaron en una oleada de dictaduras militares que en su gran mayoría impulsaron (en algunos casos de manera gradual y otros de forma radical) políticas económicas de apertura al libre mercado. Estas reformas tendieron a consolidarse -en la mayoría de los casos-, bajo Gobiernos civiles durante los noventa.

El caso más paradigmático es Chile, que tras el intento de la Unidad Popular (U.P.) de implementar la vía chilena al socialismo, se impuso una dictadura militar promovida por el gobierno norteamericano y al alero de las clases sociales dominantes chilenas- por medio de la cual se instauró un modelo capitalista neoliberal, que terminó consolidándose bajo los Gobiernos civiles de la Concertación. (Corvalán: 2002).

Estos vaivenes políticos posibilitaron que una franja de intelectuales reflexionara críticamente sobre las teorías e hipótesis de la historia chilena. Muchos de ellos, mientras se desarrollaban como intelectuales, militaban o se vinculaban a la izquierda criolla durante los '70, experimentaban la derrota de los movimientos revolucionarios, la represión y las transformaciones que se desenvolvían en el país. Así, tales fenómenos generaron en ellos importantes interrogantes que trataron de responder a través de las ciencias sociales ${ }^{4}$.

A su vez, el exilio en otros países de América y Europa posibilitó puentes de contacto con las transformaciones intelectuales que se vivieron en el viejo continente. La vida en Europa los puso al día con distintos intelectuales poco difundidos en Chile y les permitió estar cerca del debate que por esos años atravesó a las ciencias sociales sobre la pertinencia de los paradigmas explicativos hegemónicos a lo largo del siglo XX.

De allí que el Golpe de Estado de 1973 debe entenderse, además de un quiebre institucional, como un hecho que posibilitó una ruptura teórica derivada de los sucesos políticos y vivenciales para los intelectuales de izquierda en Chile (Devés 1991: 128). Produciéndose así, un desplazamiento epistemológico de estos últimos, quienes en muchos casos habían confiado en un marxismo que, parafraseando a Gramsci, los hacía creer que tenían la historia en el bolsillo (2001: 264).

\section{La apertura crítica de la Nueva Historia Social}

La expresión más importante de la historiografía critica ligada a la izquierda en la década de los ochenta, fue la corriente conocida como Nueva Historia Social. Destacan, entre otros, como sus promotores iniciales Gabriel Salazar, Leonardo León y Luis Ortega, quienes utilizaron como medio de expresión la revista Nueva Historia. Esta tendencia tuvo una variante muy similar al interior del país, que bajo la resistencia Dictatorial y a través de algunas organizaciones no-gubernamentales (ONG's) como el caso de $\mathrm{ECO}^{5}$, desarrollaron diversos estudios sociales con el objetivo de resca- 
tar la memoria y la educación popular-, aportando en la reconstrucción del tejido social con un trabajo de base en las poblaciones y el mundo popular, donde despuntó el aporte del historiador Mario Garcés (Salazar 2007: 161-163).

El esfuerzo de los nombrados historiadores por explicar la derrota de 1973 se tradujo en una crítica a los supuestos históricos y epistemológicos de la historiografía marxista clásica chilena, la cual dotó de un relato histórico al movimiento popular que alcanzó el Gobierno de Allende. Esta crítica amplia, se podría sintetizar en torno a tres ejes principales: 1) la ortodoxia teórica dicha corriente marxista; 2) su economicismo determinista del desarrollo social; y 3) la concepción del proletariado con un rol asignado naturalmente por las fuerzas de la historia.

Todo lo anterior, se basó tanto en una reflexión sobre la experiencia política vivida que esbozamos más arriba-, como de las relecturas de Karl Marx y Antonio Gramsci ${ }^{6}$, junto a la influencia de historiadores ingleses como Eric Hobsbawm ${ }^{7}$ y Edward Thompsom ${ }^{8}$. Todo confluyó en una profunda y prolífica renovación teórica y metodológica de la historia social crítica de raigambre marxista.

Con el pasar del tiempo, a los historiadores chilenos nombrados se sumaron otros, tales como Julio Pinto y Sergio Grez. Es este último quien nos sintetiza en una de sus recientes obras la reflexión crítica principal de la Nueva Historia Social, al afirmar que:

“La rigidez ideológica y epistemológica de (Ramírez Necochea, por ejemplo) contribuyó, junto al desconocimiento hasta entonces de fuentes inaccesibles, a que quedaran significativas zonas de sombras que nuevas investigaciones debían aclarar. El tinte apologético y teleológico que domina la obra de este historiador, le impidió dar respuestas adecuadas a varios fenómenos que tampoco han sido suficientemente estudiados por otros autores” (Grez 2011: 10).

El cuestionamiento de estas ideas desembocó en una revisión del desarrollo histórico del país desde una nueva perspectiva. Con este afán, los nuevos historiadores sociales se internaron en los estudios sobre los sectores populares (resignificando y ampliando la noción de proletariado), rescatando segmentos olvidados y/o marginados de ellos (Salazar 2000). Esto último se vinculaba a una relectura del peculiar carácter del desarrollo capitalista en Chile (Ortega 2005) (Salazar 2003), factores que complejizarían la composición y carácter de estos sectores sociales (Garcés 2003), matizando, condicionando y explicando sus diversas formas de organización social y política (Grez 2007, 2009 y 2011), como también su vinculación con la ideología y los planteamientos políticos más difundidos en los albores del siglo XX (Pinto y Valdivia 2001).

De tal modo, aunque los nuevos historiadores sociales analizaron una amplia gama de temas vinculados a los sectores populares, general- 
mente se enfocaron en el rango temporal que da inicio al siglo XX y no en acontecimientos cercanos al momento en que ellos investigaban. Fue sólo en casos muy específicos donde estos historiadores analizaron fenómenos cercanos al Golpe de Estado, pero tomando a actores populares poco historizados hasta ése momento, tales como los pobladores (Garcés 2001).

La obra más ambiciosa en esta perspectiva analítica se materializó en la Historia Contemporánea de Chile. Desarrollada por Salazar y Pinto (1999), buscaron plasmar un planteamiento totalizante y estructural, desde un enfoque interdisciplinario, que no obstante perder algunos elementos de la particularidad de los fenómenos históricos, constituye uno de los mayores aportes de la Nueva Historia Social a la historiografía chilena. En ella, Salazar y Pinto profundizaron los supuestos epistemológicos y ontológicos desde donde escriben. Sostuvieron que la disciplina histórica es como un abigarrado conjunto de problemas que pueden ser pensados y reflexionados colectivamente. Sucesivamente. Una y otra vez, en cada época, por cada generación de chilenos (1999: 8). Por lo que entendían su trabajo sólo como una de las distintas reflexiones posibles sobre los problemas del país, que continuaban siendo retos, desafíos y tareas para las nuevas generaciones. Como material básico para la historia que, responsablemente, debemos construir (Ibid.). De allí que pretendan
"asumir los problemas históricos de Chile desde la urgencia reflexi- va del ciudadano corriente. Es éste por ello- el sujeto, actor, y desti- natario principal del estudio.En cierto modo, es una historia mirada desde abajo; pero no desde la marginalidad, porque el ciudadano, en una sociedad, no es ni puede ser periférico a nada que ocurre en ella” (Salazar y Pinto 1999: 8).

Vemos pues, que su mirada tiene un postura crítica, que no pretende juzgar para condenar y/o glorificar, ni utilizar para ignorar su objetividad, sino para algo más trascedente e histórico: para producir y reproducir la vida social en un nivel superior (Salazar y Pinto 1999: 9).

En resumen, esta corriente historiográfica desacraliza la acción política de los sujetos sociales, especialmente de los populares, develando sus contradicciones, pero viéndolos también como sujetos activos de la historia nacional.

No obstante estas críticas y reformulaciones a los relatos sobre los sujetos populares de la historiografía marxista clásica, al igual que esta última, los nuevos historiadores sociales mantuvieron un distanciamiento aún mayor con respecto al denominado por Josep Fontana modelo académico tradicional (2004), tanto de su variante positivista como conservadora, dado que continuaron develando y poniendo en el centro del desarrollo social, la explotación, opresión y dominación de los sectores populares que ésta se empeñó en ocultar y/o marginar de sus reflexiones. De tal modo se comprenden sus planteamientos durante la década de los noventa sobre los temas que repercutían la memoria social y política contingente chilena, 
cuestión evidenciada en el impulso dado por Gabriel Salazar y Sergio Grez, $\mathrm{y}$ al que se sumaron el resto de nuevos historiadores sociales junto a muchos más intelectuales críticos, del llamado Manifiesto de Historiadores, el cual buscaba generar un relato crítico y diametralmente opuesto al planteado, en el marco de la detención de Pinochet en Londres, por historiadores conservadores, el mismo ex-Dictador y las autoridades del Gobierno Concertacionista que buscaban explicar -y de paso legitimar- la Dictadura Militar (Salazar y Grez 1999).

Si la Nueva Historia Social fue hija de su contexto, propia de la resistencia a la dictadura y el exilio, que logró renovar teórica y metodológicamente la historiografía crítica criolla, a través del re-estudio del mundo popular, ampliando sus significados y manteniendo en la mayoría de los casos- una rigurosidad de fuentes en el análisis de sus estudios, se desprendió constantemente un cuestionamiento implícito sobre el relato histórico de lo político que habían construido los historiadores conservadores del país. Dado que la Nueva Historia Social generó nuevas ideas sobre los sujetos populares y cuestionó también a los actores políticos que los decían representar, abrió la puerta para que desde esta perspectiva crítica, en el marco de los avatares y contradicciones que vivía el país a finales de los '90 y principios del siglo XXI, la historiografía se acercara al estudio de esta dimensión política de la sociedad.

\section{Los(as) historiadores(as) políticos de comienzos del siglo XXI: Las preguntas de fin de siglo y los cambios disciplinarios}

Fue bajo los Gobiernos de la Concertación de Partidos Por la Democracia cuando retornó con fuerza la preocupación por lo político en la historiografía (Ulianova 2009: 10). En este periodo, tras una década de dominación casi absoluta de las ideas económicas neoliberales, donde si bien la Nueva Historia Social había confrontado algunas afirmaciones explicativas de éstas, aún no era capaz de dar cuenta historiográficamente de las interrogantes que tenía una nueva camada de historiadores sobre la realidad contingente del país. Es así que comenzaron a surgir las preguntas sobre la forma de dominación instalada durante el Régimen de Pinochet, para dar cuenta del significado histórico de éste y de los Gobiernos de la Concertación, además de los fenómenos particulares ligados a dichos procesos. Por tanto, el reflote de lo político era causado por las distintas interrogantes que experimentaban cotidianamente las y los historiadores chilenos. Esto encontró un apoyo importante en una tendencia historiográfica que por esos años ya era bastante relevante en Europa: la denominada Historia Reciente o del Tiempo Presente ${ }^{9}$ (Moyano 2011a: 229).

Pero ésta no fue la única tendencia historiográfica mundial que había recobrado relevancia desde 1980. La crisis civilizatoria vivida por la sociedad a fines de esa década (Hobsbwam 2007), en el campo de las cien- 
cias sociales se manifestó en la llamada crisis o revisión crítica de los paradigmas del siglo XX, lo cual trajo el surgimiento de la llamada posmodernidad (Fontana 2002: 155). Esta última puso en el centro del debate disciplinario una serie de metodologías y objetos de estudio que durante gran parte del siglo XX fueron subvalorados en las ciencias sociales y la historiografía. Por tanto, con el impulso de la posmodernidad y sus lógicas fragmentarias de lo social, uno de los mayores beneficiados terminó siendo el campo de estudios sobre lo político (Altamirano 2005: 6-7).

Tras haberle dedicado gran parte del tiempo al estudio de las estructuras sociales y las instituciones políticas, en la Historia se comenzaron a rescatar los sujetos sociales y políticos (Cruz 1993: 84). La subjetividad política en Europa cobró centralidad analítica. En este ámbito, los aportes principales fueron desde el enfoque microhistórico y la deconstrucción de discursos como metodología de análisis, los cuales se venían desarrollado fuertemente desde la antropología, la lingüística y la filosofía política (Moyano 2011a: 231)

Este reposicionamiento de la Historia Política Europea, se argumentó en que la política tenía una consistencia propia, que disponía de una cierta autonomía en relación a los otros componentes de la realidad (Deloye 2004: 20) pero que, concordando con las lógicas posmodernas, no se hacía en nombre de un paradigma que declare la caducidad de los otros en nombre de un modelo historiográfico único (Altamirano 2005: 5). Estos fueron algunos de los supuestos de la llamada Nueva Historia Política francesa que, como sostiene Ives Deloye, pretendía aislar lo político de lo social y estudiar separadamente los grandes componentes estructurales de la vida política (partidos, sindicatos, mass media, elecciones) (2004: 22) y que tenía como principal exponente a René Remond (Cruz 1993). En un contexto hegemonizado progresivamente por la fragmentariedad intelectual, estas ideas lograron gran trascendencia y se transformaron en un aporte sustancial para el desarrollo de la historiografía política a escala planetaria. Empero, dada la radicalidad de su planteamiento fragmentario, provocó que salieran investigadores que matizaban su propuesta y promovieron la llamada Historia Conceptual de lo político donde su principal defensor en Francia fue Pierre Rossanvallon (Bouretz et. al. 2006), los cuales impulsan un pensamiento en bloque de lo político como lugar de acción de la sociedad sobre sí misma (Deloye 2004: 22). Así, lo político no sólo volvía al centro de la producción historiográfica, sino que estaba cruzada por profundos debates epistemológicos y ontológicos.

Todo esto fue cobrando cada vez más relevancia para la historiografía política nacional, pues la difusión de estas ideas Europeas, -en un contexto de perplejidad sobre el desarrollo político chileno, y sin una investigación disciplinaria consistente, crítica y aglutinante provocó que se transformaran en otra fuente de inspiración de la revitalización de la historiografía política chilena. 


\section{Las y los historiadores políticos chilenos del siglo XXI: producción y perspectivas}

Continuando con lo sostenido por Carlos Altamirano acerca del análisis de este proceso a nivel continental, en Chile podemos ver que más allá de una corriente o escuela particular, se evidencian más bien convergencias e intersecciones de preocupaciones que no proceden de una sola fuente de inspiración teórica (2005: 1).

En el plano nacional, quien ha realizado el mayor esfuerzo por sintetizar teórica y epistemológicamente lo ocurrido con la historiografía política en Chile, ha sido Cristina Moyano. Para ella, esta nueva forma de mirar la historia política desplazó la concepción evenementielle de corte decimonónico por una Historia social de lo político (2010). Buscando superar la mirada descriptiva de la política, penetr(a) comprensivamente en los fenómenos traumáticos del siglo XX(Ibid: 2).

Podríamos agregar que este tipo de análisis ha tenido un carácter plural y diverso en cuanto a sus objetos de estudios específicos. Aunque se pueden estructurar en dos grandes tendencias de investigaciones, que se explican por las influencias teóricas de dos generaciones de historiadores políticos. Por un lado, están aquellos que pretenden mantener una historia política con horizonte de totalidad o, al menos, que trata de interrelacionar a distintos actores del pasado reciente nacional. En esta línea, se ha analizado críticamente el desarrollo del sistema de partidos políticos entre 1932 y 1973 (Moulian 2006), como también el supuesto carácter democrático del Régimen institucional durante el mismo período (Gómez 2004). Otros estudios han buscado dar cuenta de la antagónica relación entre izquierdas y derechas desde 1973 hasta 1990 (Valdivia et. al. 2006 y 2008a). También, se ha releído las relaciones de dominación, visibilizando el rol de la violencia social y política durante el Siglo XX (Goicovic 2004 y 2012). En esta perspectiva, quizás uno de los estudios más ambiciosos es aquél que ha buscado explicar globalmente lo sucedido en materia de historia política a lo largo de la segunda mitad del siglo XX (Corvalán 2002). Estos historiadores, formados durante los '80 y principios de la década del ' 90 , si bien tratan de hacer una revisión de las metodologías y de los supuestos epistemológicos de las teorías historiográficas hegemónicas durante el siglo XX, mantienen una distancia con las miradas posmodernas.

Pero la amplitud de las investigaciones históricas sobre lo político, ha abarcado también una revalorización de los sujetos y la subjetividad, enfocándose, por tanto, en fenómenos particulares del pasado reciente. Tomando el aporte de los estudios europeos, se han rescatado a las organizaciones políticas desde nuevos enfoques (Moyano 2009; Bravo 2010) para hacer una relectura de ellos y sus trayectorias. Esto ha posicionado el concepto de cultura política para comprender a las colectividades (Moyano 2009; Álvarez 2012). También se han incluido perspectivas comparadas de distintos movimientos y fenómenos políticos en países del continente (Leiva 
2010; Pérez y Pozzi 2012). Una recopilación de algunos esfuerzos historiográficos de esta índole, ha quedado plasmada en un libro compuesto por diversos artículos particulares que rescatan el rol de líderes políticos del movimiento obrero chileno en otros países, de la mujer, los inmigrantes, los jóvenes e identidades poco estudiadas desde el punto de vista político, así como los contactos entre la cultura y la política (Ulianova 2009).

Esta última tendencia agrupa a una generación de historiadores políticos que se formó a mediados de la década del '90 y comienzos del siglo XXI. Ellos desde un enfoque más ecléctico epistemológicamente, han tratado de sintetizar de distinta manera las corrientes teóricas y metodológicas de la historiografía contemporánea, por lo que no pueden ser etiquetadas bajo una sola corriente de pensamiento.

Dichas características manifiestan que los historiadores políticos críticos chilenos del siglo XXI sustentan su trabajo en distintos supuestos y propuestas para su quehacer. Para profundizar en este análisis, hemos tomado lo planteado por algunos de estas y estos historiadores. Sobre la primera tendencia rescataremos lo afirmado por Luis Corvalán Marquéz y por Juan Carlos Gómez Leyton, y sobre la segunda a Cristina Moyano.

Si bien Corvalán Marquéz y Gómez Leyton pueden ser clasificados como parte de una tendencia de historiadores políticos similares, su propuesta investigativa no es la misma. El primero ha centrado sus preocupaciones particularmente en torno al golpe de Estado de 1973 (Corvalán 2002). Tal como nos señaló en una entrevista ${ }^{10}$, su producción historiográfica parte de un cúmulo de procesos biográficos que significan su presente, los cuales descansan en su memoria como sujeto político. Según él, sus preguntas acerca de la realidad social parten con el Golpe de Estado y el rol jugado por las FF.AA, buscando explicar por qué la extrema violencia de estas aun cuando la izquierda después del golpe estaba liquidada militarmente (Corvalán 2011).

Pero también su obra tiene un claro sentido teórico-político de índole crítico. En efecto, sus principales trabajos se dan justo en el cruce temporal del siglo XX y XXI, momento cuando se daba un incipiente debate en el país sobre cómo caracterizar el pasado reciente, debate que, sin duda tiene un trasfondo político (Corvalán 2002: 11). Corvalán, planteaba que el afán de releer la historia política nacional reciente, en ése momento despertaba alarma entre los vencedores (de los hechos relatados), que con el control ilimitado tanto del poder político como de los medios de transmisión de ideas, convirtieron sus discursos legitimantes en tesis historiográficas (Ibid.). Por ello, manifestaba que su trabajo se sitúa(ba) en una perspectiva claramente revisionista (Ibid.). Vemos pues, que Corvalán tiene una postura opuesta a la historiografía política tradicional y conservadora.

Más aún, el autor se identifica con posiciones epistemológicas ligadas al materialismo histórico, apostando a intentar reconstruir la totalidad de aspectos que ayuden a comprender un determinado fenómeno político- 
social. El autor ha sostenido que no es partidario de pensar la realidad de modo objetivista o desde una inocente neutralidad de lo científico, teniendo la impresión de que eso es una ideología también (Corvalán 2011). Para él, la realidad puede ser explicada por la historiografía, por lo que no comparte el supuesto de que lo que existe es el conjunto de representaciones que puede variar de acuerdo a una lógica interna, y que el mundo no es más que una proyección de esa lógica, sea de discurso, lenguaje u otra cosa (Ibid.). Del mismo modo, se aleja del objetivismo tradicional que se basa en la idea

“de que la realidad existe, que también existen dificultades para acceder a ella y eso se resuelve por la vía del método. Entiendo que la realidad está mediada por las representaciones del mundo, y que aquella está condicionada por las representaciones de ese mundo y esto claro me conecta un poco con el giro lingüístico, pero sólo aparentemente- porque allí salta la pregunta sobre el origen de ese conjunto de representaciones, ante esa pregunta respondo desde el marxismo, es decir que estas construcciones representativas del mundo provienen del lugar en que se esté situado en la realidad” (Corvalán 2011).

Precisando que ese lugar es siempre social, formando parte de una clase o cultura, con intereses que se presentan universalizados o naturalizados, como los del propio historiador. Allí, reconoce que la postura que tenga este último, no es la única, ni pura ni verdadera, por lo que al interior de la disciplina también se da un debate entre diversos puntos de vista, asumiendo el discurso del historiador como un constructo teórico-político.

Desde esta óptica, Corvalán ha tratado de precisar su concepción de la política, la cual entiende sólo como una dimensión de la compleja realidad social, teniendo como premisa el principio de totalidad. Es decir, una visión que concibe a la sociedad como la articulación orgánica de distintos planos interdependientes. Desde esta óptica teórica, la historia política emerge como una historia de síntesis de todas las demás historias (2009: 7). Este principio y perspectiva facilitaría la comprensión de la misma. Apuntando a que la historia política que concebimos inevitablemente requiere integrar los conocimientos que aportan las otras disciplinas de las ciencias sociales (Ibid.). Todo lo que decantaría en una historiografía política analítica y explicativa, una historia que visualice los más diversos procesos verificados en la sociedad, sintetizados y expresados a nivel del Estado y de las luchas por su control, lo que implica sujetos, proyectos, discursos legitimantes, ideologías, intereses etc (Ibid.).

Según esto último, podemos señalar que Corvalán expande hacia la historia política los planteamientos realizados por los nuevos historiadores sociales. Refresca para ello la idea de totalidad y materialidad. Al mirar desde un prisma materialista-histórico los estudios políticos, pretende colaborar en llenar el vacío que la escuela marxista clásica dejó sobre esta dimensión de la sociedad. En síntesis, Corvalán demuestra cómo el pensa- 
miento crítico y las ideas vinculadas al marxismo han sido una afluente para la revitalización de la historiografía política nacional.

En una senda similar, Juan Carlos Gómez ha planteado la necesidad de abordar la historia política reciente del país a través de la superación de las lógicas fragmentarias tradicionales de las ciencias sociales. Sus investigaciones parten de la premisa de que la historia política había sido ampliamente descuidada por los historiadores y, no necesariamente, por otros cientistas sociales tales como: politólogos o sociólogos políticos; los cuales han abordado de manera mucho más directa la historia reciente de Chile (Gómez 2009: 49). Lo preocupante para él, sin duda es que la historiografía de orientación democrática y popular ha(bía) descuidado el análisis de la historia política, especialmente, la que se refiere al siglo XX en general y, a la historia política reciente, en particular (Ibid.). Realizando una clara crítica al distanciamiento de lo político y del pasado reciente por parte de la historiografía marxista clásica y la Nueva Historia Social.

Según Gómez, la historia política reciente, requiere ser explicada tanto histórica como politológicamente (2009: 50), para lo cual se necesitaría de un ejercicio epistemológico que involucre a dos disciplinas de las ciencias sociales, aparentemente distantes: la ciencia política y la historia (Ibid.). Esto se materializaría en combinar la investigación histórica, la narrativa historicista y la analítica politológica (Ibid: 52), caminando por la senda de la interdisciplinariedad. Así, se podría ir forjando una Ciencia Política Histórica, que se debería proponer estudiar políticamente el pasado histórico para generar un conocimiento útil, a fin de enfrentar el presente o futuro. En ese sentido, debiera tender a producir teoría política y, también interpretación histórica (Ibid: 51). De allí que pretenda avanzar más allá de la mera historia política que,-según Gómez- se enfoca sólo en reconstruir los hechos políticos relevantes de una sociedad dada, dar cuenta de sus conflictos y, por cierto-a veces-, explicar el cambio político (Ibid.). Por su parte, él propone con la Ciencia Política Histórica analizar los procesos políticos, la política, el poder, las fuerzas políticas en periodos o lapsos históricos específicos (Ibid.). Cuestión que para lograrse, debe utilizar todo el instrumental teórico, conceptual como metodológico de la ciencia política (Dado que) son muy pocos los historiadores que utilizan las herramientas proporcionadas por la ciencia política en sus estudios de historia política (Ibid.). Esta proposición de la Ciencia Política Histórica, que con su lógica busca desbordar y superar desde una perspectiva interdisciplinaria la historiografía política, consideramos que lo diferencia de lo planteado por Corvalán, el cual hace sus planteamientos sólo para la Historia, pero lo aleja aún más de las lógicas fragmentarias impulsadas por la posmodernidad.

Empero, coincide con el enfoque crítico de Corvalán, al proponer que la Ciencia Política Histórica se asuma como una disciplina abierta a la formulación de problemas políticos que se ubican ya sea en el pasado reciente como en el pasado lejano (Gómez 2009: 51), cuestiona la lógica tradicional de las ciencias sociales y pone en el centro de la ciencia política 
una premisa epistemológica sustancial del planteamiento crítico: todo problema científico se formula teniendo como marco referencial el presente (Ibid: 51-52). Siguiendo esta idea, podemos comprender que sus esfuerzos investigativos los realice en lo que para él es uno de los problemas prioritarios de la Ciencia Política Histórica: la cuestión de la democracia en Chile.

Por otra parte y desde un enfoque distinto, la historiadora Cristina Moyano ha planteado que se ubicaba desde una perspectiva heterodoxa, sin un paradigma fijo, estático y definido, tendiendo a utilizar conceptos o herramientas teóricas de acuerdo a las necesidades investigativas dadas. Ella en particular, se basaría en dos premisas fundamentales: primero, entendiendo a la realidad como constructo, donde las condiciones materiales importan, en la medida de que los sujetos las nominen como tales (2011b); y segundo, el concepto de categoría, entendido como etiqueta de la realidad que a la vez tiene un carácter performativo ${ }^{11}$. Como vemos, a la inversa de lo planteado por Corvalán, para Moyano es la subjetividad y la conciencia de los sujetos las que ponen en relevancia determinados fenómenos sociales.

Estos supuestos teóricos le habrían permitido crear un interesante campo de investigación, a través de la importación desde Europa de los análisis sobre las culturas, redes, militancia y del leguaje político. A ello ha sumado reflexiones sobre la forma de abordar las fuentes para el estudio de las dimensiones subjetivas de la política, tales como los testimonios, la memoria y los conceptos, desde la perspectiva teórica elaborada por Reinhart Koselleck y Quentin Skinner.

Por lo anterior, la autora se identifica dentro de la influencia de la escuela de Cambridge y la alemana Begriffsgeschichte (Vilanau 2006: 167). Desmarcándose del giro lingüístico, a través de las propuestas de dichas corrientes, trata de no descuidar la influencia del campo de lo social en la producción de los conceptos políticos. Al respecto sostuvo: es interesante la preocupación por el lenguaje, pero no comparto el reduccionismo a esto. Creo que lo relevante es entorno a la disputa por los conceptos, de ahí que me acerque a Koselleck (Moyano 2011b). La historiadora concluye que no hay ideas en abstracto y que las reflexiones políticas y los conceptos movilizan la acción política (de ahí su preocupación por el lenguaje político y los modos y usos del habla ${ }^{12}$ (Ibid). En este sentido, para Moyano la disputa por los conceptos es también una disputa política, resignificando el concepto de poder desde la perspectiva de Michael Foucault (1993).

Con todo, marca un quiebre radical con la historiografía decimonónica y con las tendencias totalizantes, lo cual ejemplifica a través de su trabajo enfocado en uno de los principales actores de la política: los Partidos. Éstos, para Moyano, deben ser comprendidos a través de sus lógicas internas y particulares, donde los ejercicios significativos que realizan sus integrantes son claves. De allí que afirme críticamente que un análisis hiper racional no permite entender los cambios al interior de un partido 
político, puesto que piensa a éste como un ente estático, por el contrario el partido está en permanente construcción (2011b). Llevándola a redefinir las organizaciones políticas como una comunidad de sujetos y actores.

En esta línea, el rescate de la subjetividad resulta de la comprensión sobre la complejidad del desarrollo político, que la lleva a tomar la noción de Norbert Lechner de cultura política ${ }^{13}$. Realizando una lectura de lo planteado por este autor, Moyano la entiende como una síntesis comprensiva o el modo en que un movimiento entiende la actuación política y simbólica de sus miembros dentro de la construcción de un orden social determinado; la significación que realizan de su actuación; las luchas por la búsqueda de las hegemonías del recuerdo y del presente (2009: 52). Resumiendo, desde esta resignificación de lo político entiende al Partido como una comunidad de sujetos, que no se materializa y explica tan sólo a través de sus documentos oficiales o declaraciones de congresos, sino que también en la construcción cotidiana de sus militantes en la interacción de una cultura política.

Tomando lo antes dicho, para la autora estos elementos serían los que considera como medulares de la historia social de lo político, la cual recogería las herramientas conceptuales de la nueva historia social, pero aplicadas a los fenómenos de la política.

Ahora bien, Moyano sostiene que los esfuerzos realizados durante los '80 y '90 por los nuevos historiadores sociales-principalmente por su afán de buscar respuestas al Golpe de Estado y la Dictadura en el surgimiento del movimiento popular a comienzos del siglo XX-, los habría llevado a dejar de lado los problemas sobre las relaciones de poder bajo la misma Dictadura Militar y los Gobiernos de la Concertación, planteando que ellos no escribían sobre lo que estaba sucediendo (Moyano 2011b).

Este espacio en blanco la llevó a conectar la historia social de lo político con la denominada Historia del Tiempo Presente. En efecto, su consideración del carácter político de la preocupación historiográfica del presente -basada en la noción de disputa de los conceptos y por ende de la(s) memoria(s) misma-, la empujó a sumergirse en una amplia gama de fenómenos históricos, que van desde la década del sesenta, pasando por la Dictadura Militar, la llamada transición a la democracia hasta los Gobiernos de la Concertación. En este proceso, si bien se nutrió de algunos elementos del ejercicio de la Nueva Historia Social, terminó por distanciarse del rango temporal de los estudios de ésta última.

Podemos evidenciar, que esta autora ha sido una de las que más ha tratado de sistematizar y sintetizar el desarrollo de la Nueva Historia Política y por la llamada Historia conceptual de lo político, para abordar de manera novedosa fenómenos descuidados por la historiografía durante casi todo el siglo XX, marcando el distanciamiento más claro en comparación con los historiadores políticos analizados anteriormente- con los supuesto epistemológicos del siglo XX. 
En base a lo antes dicho, podemos ver claramente como en Chile el proceso de revitalización de la historiografía política se nutre del desarrollo de los nuevos enfoques que se han dado con fuerza en Europa, pero matizados por una serie de elementos propios, cuestión condicionada por el contexto histórico del país, especialmente con respecto a la perspectiva crítica de la historiografía tradicional que ha asumido. Es así que se da una mixtura muy enriquecedora de análisis del desarrollo político en la última centuria.

Dada estas diversas fuentes de las cuales se nutre la historiografía política, ha sido complejo un planteamiento teórico y epistemológico que sintetice de manera precisa y coherente el entendimiento de esta dimensión de la realidad social. Por ello, consideramos que este es un vacío que no ha sido llenado con claridad por la historiografía política crítica del pasado reciente nacional.

\section{Conclusiones}

En el desarrollo de este trabajo analizamos algunos elementos que permiten comprender la revitalización de la historiografía política durante los últimos años en nuestro país. Desde un análisis de fuentes, tanto bibliográficas como orales, vimos las distintas vertientes de las que se nutrió este proceso, lo que nos lleva a sugerir que:

1.- Un factor de largo plazo que contribuyó, fue el complejo contexto histórico experimentado por el país durante los últimos años. Los vaivenes vividos desde 1970 en adelante, marcó a varias generaciones de historiadores chilenos. En éstos, de a poco se fueron posicionando las preguntas sobre lo político. Tras la crítica a la historiografía basada en el modelo académico tradicional, tanto decimonónica y conservadora, como también a la marxista clásica, realizada por los nuevos historiadores sociales, se comenzó a gestar una generación de historiadores que buscarían explicar el devenir del país a través de las problemáticas políticas recientes.

2.- Este reposicionamiento de lo político se fortaleció por los cambios que se vivían a nivel mundial en el seno de las ciencias sociales en general, y de la historiografía en particular. La crisis de los grandes paradigmas, la posmodernidad y los intercambios metodológicos y epistemológicos entre las diversas ciencias sociales, repusieron al sujeto en el centro de las investigaciones historiográficas. Así la política cobró nuevamente un rol protagónico, pero atravesada por nuevas preguntas y respuestas. Las relaciones entre el sujeto y la totalidad social, el rol de la subjetividad, el lenguaje, las culturas políticas y la memoria, se trataron de responder con aportes de la antropología, la lingüística, la sociología y la filosofía, por nombrar algunas. Pero también las interrogantes sobre los hechos traumáticos del siglo XX cobraron relevancia en los estudios históricos a escala planetaria. Con todo, se cruzaron de manera espontánea y fragmentaria, una serie de necesidades y trabajos académicos en las ciencias socia- 
les y en la historiografía mundial, que al andar fueron reconfigurando premisas y generando nuevas tendencias, aunque manteniendo diferentes proyecciones acerca del quehacer historiográfico. Emergieron con fuerza algunas escuelas, especialmente en Francia, tales como la Nueva Historia Política y la Historia Conceptual de lo político. Dado el progresivo escepticismo con respecto a las corrientes historiográficas hegemónicas mundiales del siglo XX, estas nuevas tendencias ofrecieron sugerentes alternativas teóricas, epistemológicas y metodológicas a algunos historiadores chilenos de la camada que se preguntaba sobre lo político en el país.

3.- Fue hacia finales del siglo XX y comienzo del XXI cuando cobraron relevancia académica los historiadores políticos críticos del pasado reciente chileno. Tomando el ejercicio crítico realizado por los nuevos historiadores sociales, han intentado impulsar una especie de historia social de lo político, que tuviera en cuenta distintos factores no abordados por la historiografía tradicional para entender esta dimensión social. De tal modo reflexionaron sobre lo político de una manera renovada y novedosa, en cuanto a las metodologías, objetos de estudio y, por cierto, a las hipótesis planteadas. Ahora bien, al igual que a nivel mundial, esto se dio de manera fragmentaria y sin un paradigma único detrás, impidiendo que lo obrado se pueda describir como el fruto de una escuela historiográfica particular, sino que como una convergencia entre distintas necesidades analíticas.

4.- Entre los objetos de estudio de los historiadores políticos críticos han estado, principalmente, los hechos acaecidos desde los años 60 hasta los Gobiernos Concertacionistas. Junto con los distintos fenómenos particulares que le han dado forma a este extenso período, se han intentado mirar desde nuevas ópticas y un utillaje teórico más preciso.

5.- Ahora bien, los enfoques han sido muy diversos. En el desarrollo de este texto, hemos profundizado lo propuesto por una primera generación de historiadores políticos, quienes desde un lente materialista histórico han mantenido un horizonte de totalidad para comprender sus respectivos estudios. Para ello han tratado de explicar fenómenos globales y/o estructurales del desarrollo social, proponiendo estrechar los lazos con otras ciencias sociales.

Una segunda generación de historiadores políticos ha profundizado en estudios particulares. Si bien existe una diversidad de perspectivas analíticas entre estos últimos, un rasgo común es su ecléctica visión con respecto a las investigaciones, sin una teoría específica que los guíe. Éstos, en la mayoría de los casos han abierto sus análisis a las reflexiones provenientes desde la Nueva Historia Política, la Historia Conceptual de los Políticos y la Historia del Tiempo Presente.

Estos factores, a la hora de hacer un balance, evidencian que en Chile, la revitalización de la historiografía política ha ido constituyendo un mosaico entre diversas concepciones teóricas y epistemológicas. Aunque en lo general este rasgo asimile a lo sucedido en Chile y en el mundo, en lo 
particular esto trae consigo elementos que distancia a la historiografía política chilena con respecto a la Nueva Historia Política Europea. En efecto, si bien el caso de los historiadores chilenos se nutre del avance disciplinario en Europa, sus planteamientos se distancian en cuestiones centrales de los promotores de esta corriente francesa, tales como la mantención de perspectivas totalizantes de raigambre materialista-histórica. Por lo que homologar ambos fenómenos es insostenible, siendo poco demostrativo de lo sucedido en Chile su identificación como una Nueva Historia Política.

De allí, que lo más relevante e identitario de éste proceso de revitalización de la historiografía política, más que un paradigma o supuestos epistémicos aglutinantes es, además del objeto de estudio (lo político), su afán crítico y revisionista. Crítico, pues su principal motor y ejercicio teórico e investigativo es el constante cuestionamiento de las hipótesis en boga sobre los fenómenos políticos. Revisionista, ya que pone en tela de juicio fundamentalmente las premisas políticas establecidas por la historiografía tradicional para generar nuevas lecturas. Deviniendo en un proceso de revitalización de la historiografía política nacional, desde una perspectiva crítica, que ha ido llenando progresivamente un vacío historiográfico que ésta dejó a lo largo del siglo XX. 


\section{Notas}

${ }^{1}$ Aspectos parciales de este artículo fueron presentados en el XI Seminario Argentino Chileno y V Seminario del Cono Sur de Ciencias Sociales, Humanidades y Relaciones Internacionales, 7,8 y 9 de Marzo 2012. Universidad de Cuyo, Mendoza, Argentina. Organizadas por la Universidad Nacional de Cuyo y Conicet.

${ }^{2}$ Dentro de los denominados historiadores marxistas clásicos se encuentran Hernán Ramírez Necochea, Julio César Jobet, Fernando Ortiz Letelier y Marcelo Segall entre otros. Para un análisis de la vinculación entre la historiografía chilena y las corrientes mundiales, véase (Gazmuri 2007)

${ }^{3}$ Dentro de ellos incluimos a la tradición historiográfica compuesta por Agustín Edwards, Jaime Eyzaguirre, Francisco Encina, Bernardino Bravo Lira y Gonzalo Vial Correo. Para un análisis más profunda véase (Corvalán 1998) (Jocelyn-Holt 2007) (Gazmuri 2007).

${ }^{4}$ Un análisis exhaustivo de éste tema véase (Salazar 2007: 155-167).

${ }^{5}$ Organización no-gubernamental Educación y Comunicaciones.

${ }^{6}$ Intelectual marxista italiano, muerto en la década de los treinta bajo la Dictadura de Mussolini. Véase (Gramsci 2001)

${ }^{7}$ Historiador marxista inglés. Sus principales reflexiones se materializaron en el ámbito de la historia de las sociedades capitalistas. Su trabajo más ambicioso es la serie de libros conocido como las Eras de la historia contemporánea, compuesta por: La era del capital, La era de las revoluciones, La era del Imperio y La Historia del Siglo XX.

${ }^{8}$ Historiador marxista inglés, coetáneo de Hobsbawm. Desarrolló su trabajo en la historia de cultura popular. Sus aportes más trascendentales se vinculan con las clases sociales y su conciencia. Junto con ello, es conocido por su debate con el marxista estructuralista francés Louis Althusser.

${ }^{9}$ Dadas las distintas conceptualizaciones surgidas al calor de los estudios sobre la historia temporalmente reciente, usaremos el término Historia Reciente. Esto porque, en el caso chileno, la memoria y la subjetividad se ha condensado en torno a temas traumáticos temporalmente recientes. Sobre el desarrollo de la historia del tiempo presente (Soto 2004) y algunas reflexiones sobre ella, las compilaciones de (Bresciano 2010) (López, Figueroa y Rajland 2010).

${ }^{10}$ Entrevista realizada el Martes 19 de Julio de 2011.

${ }^{11}$ Entrevista a Cristina Moyano Lunes 18 de Julio de 2011. (Moyano 2011b)

${ }^{12}$ Para una aplicación de esto véase (Moyano; 2011b)

${ }^{13}$ El cientista político alemán Norbert Lechner es una importante influencia en la autora. Dentro de sus obras donde trata estos temas podemos destacar (Lechner, 1988). 


\section{Bibliografía}

Altamirano, Carlos (2005), "De la Historia Política a la Historia Intelectual. Reactivaciones y Renovaciones”, en Prismas, Revistas de Historia Intelectual, $\mathrm{N}^{\circ}$ 9. Consulta 12 de Julio del 2011: http://historiapolitica.com/ datos/biblioteca/xixaltamirano.pdf

Álvarez, Rolando (2011), Arriba los pobres del mundo. Cultura e identidad política del Partido Comunista de Chile entre democracia y dictadura. 1965-1990, Lom, Santiago.

Bouretz, Pierre et. al. (2006), Hacer la historia de lo político. Entrevista con Pierre Rosanvallon, Memoria \& Sociedad, Vol. 10, $\mathrm{N}^{\circ} 20$. Consultado el 20 de Julio del 2011: http://www.javeriana.edu.co/Facultades/C_Sociales/ memoria/MEMORIA20/ROSANVALLON.pdf

Bravo, Viviana (2010), ¡Con la Razón y la Fuerza, Venceremos! La Rebelión Popular y la Subjetividad Comunista en los '80, Ariadna, Santiago.

Bresciano, Juan (comp.) (2010), El tiempo presente como campo historiográfico. Ensayos teóricos y estudios de casos, Cruz del Sur, Uruguay.

Borón, Atilio (2006), “Clase inaugural: Por el necesario (y demorado) retorno al Marxismo”, en Borón, Atilio, et. al. Teoría Marxista. Problemas y perspectivas. Clacso, Buenos Aires. Consulta el 15 de Julio del 2011: http://bibliotecavirtual.clacso.org.ar/ar/libros/campus/marxis/marxis.pdf

Corvalán, Luis (1998), “Notas Preliminares para un estudio sobre la relación entre historiografía y política en el pensamiento conservador chileno”, en Encuentro XXI, Año 4, N 13. Santiago de Chile.

Idem (2002), Del anticapitalismo al neoliberalismo en Chile. Izquierda, centro y derecha en la lucha por los tres proyectos globales. 1950-2000, Sudamericana, Santiago de Chile.

Idem (2009), “Prólogo”, en Rios, Nicole (ed.) Para el análisis del Chile Contemporáneo: Aportes desde la Historia Política, Valparaíso, Chile.

Cruz, María (1993), “En torno a la Nueva Historia Política francesa”, en Historia Contemporánea, N 9, 25-35, Consultado el 12 de Agosto, 2012. Disponible en: http://www.historiacontemporanea.ehu.es/s0021-con/es/ contenidos/boletin_revista/00021_revista_hc09/es_revista/adjuntos/ 09_05.pdf

Deloye, Ives (2004), Sociología histórica de lo político, Lom, Santiago.

Devés, Eduardo (1991), “La cultura obrera ilustrada chilena y algunas ideas en torno al sentido de nuestro quehacer historiográfico”, en Revista 
Mapocho, N 30, Dibam, Santiago de Chile.

Fontana, Josep, (2004), La historia de los hombres: el siglo XX, Critica, Barcelona.

Foucault, Michael (1993), Microfísica del Poder, La Piqueta, Madrid.

Garcés, Mario (2002), Tomando su sitio. El movimiento de pobladores de Santiago, 1957-1970, Lom, Santiago.

Idem (2003), Crisis social y motines populares en el 1900, Lom, Santiago de Chile.

Gazmuri, Cristián (2007), “Influencias sobre la historiografía chilena: 18421970”, en Luis de Mussy (ed.) Balance historiográfico chileno. El orden del discurso y el giro crítico actual. Santiago de Chile, Finis Terrae. pp. 75-94.

Goicovic, Igor (2004), “Consideraciones teóricas sobre la violencia social en Chile (1850-1930)”, en Última Década, № 21, Valparaíso, 121-145. Consultado: 10 de Julio del 2012. Disponible en: http://www.cidpa.cl/wpcontent/uploads/2012/06/udecada21art06.pdf

Idem (2012), “El Movimiento de Izquierda Revolucionario (MIR) y la irrupción de la lucha armada en Chile, 1965-1990”, en Pérez, Claudio y Pablo Pozzi (eds.) Historia Oral e Historia política. Izquierda y lucha armada en América Latina, Lom, Santiago de Chile.

Gómez, Juan Carlos (2004), La Frontera de la Democracia. El derecho de propiedad en Chile. 1925-1973, Lom, Santiago de Chile.

Idem. (2009), "Democratización y Democracia en la Historia Política reciente de Chile”, en Ríos, Nicole (ed.), Para el análisis del Chile Contemporáneo: Aportes desde la historia política, Valparaíso, Chile.

Gramsci, Antonio (2001), “Sobre el Marxismo Vulgar”, en Manuel Sacristán (ed), Antología, Siglo XXI, Buenos Aires.

Grez, Sergio (2007), De la regeneración del pueblo a la huelga general. Génesis y evolución histórica del movimiento popular en Chile (1810-1990), Ril Editores, Santiago.

Idem. (2009), Los anarquistas y el movimiento obrero. La alborada de la Idea en Chile (1893-1915), Lom, Santiago.

Idem. (2011), Historia del Comunismo en Chile. La era de Recabarren, 1912-1924,Lom, Santiago.

Hobsbawm, Eric (2007), Historia del siglo XX, Crítica, Buenos Aires, Crítica. 
Jocelyn-Holt, Alfredo, “Balance historiográfico una primera aproximación al Canon”, en Luis de Mussy (ed.) Balance historiográfico chileno. El orden del discurso y el giro crítico actual, Finis Terrae, pp. 31-74, Santiago de Chile.

Lechner, Norbert (1988), Los patios interiores de la democracia. Subjetividad y política, Flacso, Santiago. Consultado el 10 de Julio del 2011. Disponible en: http://cronopio.flacso.cl/fondo/pub/publicos/1988/libro/ 000042.pdf.

Leiva, Sebastián (2010), Revolución Socialista y Poder Popular. Los casos del MIR y el PRT-ERP 1970-1976, Escaparate, Santiago de Chile.

López Sánchez, Roberto (2000), “La crisis de paradigmas en la Historia, Las nuevas tendencias historiográficas y la construcción de nuevos paradigmas en la investigación histórica”, en Espacio Abierto, Julio-Septiembre, año/vol. 9, número 003, p. 319-414, Venezuela.

López, Margarita; Carlos Figueroa y Beatriz Rajland (eds.) (2010), Temas y procesos de la Historia Reciente de América Latina, ARCIS-CLACSO, Santiago de Chile.

Monsalvez, Danny (2010), Los combates por nuestra historia: Nueva historia política e historia del tiempo presente, Santiago de Chile. Consulta 15 de Julio del 2011: http://www.estudioshistoricos.cl/blog/los-combatespor-nuestra-historia-nueva-historia-politica-e-historia-del-tiempo-presente/

Moulian, Luis (1997), “Marx y la historiografía chilena”, en Encuentro XXI. Año 3, N 8. Santiago de Chile. Consulta 14 de Julio del 2011: http:/ /encuentroxxi.net/XXI_8/EXXI_8_Moulian.pdf

Moulian, Tomás (2006), Fracturas: de Pedro Aguirre Cerda a Salvador Allende (1938-1973), Lom, Santiago.

Moyano, Cristina (2010), Elementos teóricos y metodológicos para estudiar los partidos políticos y a la militancia, Valparaíso, Chile. Consultado el 17 de Julio del 2011: http://cristinamoyano.files.wordpress.com/2010/ 11/10-10-15iv-jornadas-de-historia-politica-conferencia-magistral.pdf

Idem (2011a), “La historia política en el bicentenario: Entre la historia del presente y la historia conceptual. Reflexiones sobre la nueva historia política”, en Revista de Historia Social y de las Mentalidades, $N^{\circ} 15$, Volumen 1, Santiago de Chile. Consulta el 18 de Julio del 2011: http:// rhistoria.usach.cl/articulo_b.php?artid=195

Idem (2011c), “Diálogos entre el exilio y el interior. Reflexiones en torno a la circulación de ideas en el proceso de renovación socialista, 1973-1990”, en RevistaIzquierdas, $\mathrm{N}^{\circ}$ 9, Santiago de Chile, 31-46. Consultado el 10 de Mayo del 2011. Disponible en: http://www.izquierdas.cl/revista/wp-content/ 
uploads/2011/07/Cristina-Moyano.pdf.

Idem (2009), MAPU o la seducción del poder y la juventud. Los años fundacionales del partido-mito de nuestra transición (1969-1973), Universidad Alberto Hurtado, Santiago de Chile.

Ortega, Luis (2005), Chile en ruta al capitalismo. Cambio, euforia y depresión 1850-1880, Dibam-Lom, Santiago de Chile.

Palacios, Guillermo (2007), "Entre una Nueva Historia y una Nueva Historiografía para la Historia Política de América Latina en el siglo XIX”, en Guillermo Palacios (coord.) Ensayos sobre la nueva historia política de América Latina S. XIX, El Colegio de México, México. Consulta 12 de Julio del 2011: http://historiapolitica.com/datos/biblioteca/xixpalacios.pdf

Pérez, Carlos (2008), Sobre un concepto histórico de ciencia. De la epistemología actual a la Dialéctica, Arcis-Lom, Santiago de Chile.

Pérez, Carlos (s/f), Proposiciones de un marxismo hegeliano, Arcis, Santiago de Chile.

Pérez, Claudio y Pablo Pozzi (eds.) (2012), Historia Oral e Historia política. Izquierda y lucha armada en América Latina, Lom, Santiago de Chile.

Pinto, Julio y Verónica Valdivia (2001), ¿Revolución proletaria o querida chusma? Socialismo y Alessandrismo en la pugna por la politización pampina (1911-1932), Lom, Santiago de Chile.

Pinto, Julio (2008), “El punto de quiebre: El MIR en los ochenta en Valdivia”, Verónica et. al. Su revolución contra nuestra revolución. Vol.II. La pugna marxista-gremialista en los ochenta, Lom, Santiago.

Salazar, Gabriel y Julio Pinto (2004), Historia contemporánea de Chile, Lom, Santiago de Chile.

Salazar, Gabriel. (2000), Labradores, peones y proletarios, Lom, Santiago de Chile.

Salazar, Gabriel. (2003), Historia de la Acumulación Capitalista en Chile, 2003, Lom, Santiago.

Salazar, Gabriel (2007), “Historiografía chilena siglo XXI: transformación, responsabilidad y proyección”, en Luis de Mussy (ed.) Balance historiográfico chileno. El orden del discurso y el giro crítico actual. Santiago de Chile, Finis Terrae. p. 95-167.

Salazar, Gabriel y Sergio Grez (1998), Manifiesto de Historiadores, Lom, Santiago de Chile. 
Sinelli, Jean-Francois (1993): “El Retorno de lo político”, en Historia Contemporánea, $\mathrm{N}^{\circ}$ 9, 25-35. Consultado el 12 de Agosto, 2012. Disponible en: http://www.historiacontemporanea.ehu.es/s0021-con/es/contenidos/ boletin_revista/00021_revista_hc09/es_revista/adjuntos/09_03.pdf

Soto, Ángel (2004), “Historia del Presente: Estado de la cuestión y conceptualización”, en Historia Actual Online. $\mathrm{N}^{\circ} 3$, Invierno. Santiago de Chile, p. 101-116.

Ulianova, Olga (ed.) (2009), “La historia política está de vuelta”, en Redes y militancia Política. La Historia Política está de vuelta, Ariadna Ediciones, Santiago de Chile.

Ulianova, Olga y Alfredo Riquelme (2009), Chile en los archivos soviéticos 1922-1991. Tomo II: Komitern y Chile (1931-1935), Dibam-Lom, Santiago de Chile.

Valdivia, Verónica et. al. (2006), Su revolución contra nuestra revolución. Izquierdas y Derechas en el Chile de Pinochet. (1973-1981), Lom, Santiago de Chile.

Idem. (2008a), Su revolución contra nuestra revolución. Vol. II. La pugna marxista-gremialista en los ochenta, Lom, Santiago de Chile.

Valdivia, Verónica (2008b), Nacionales y gremialistas. El parto de la nueva derecha política chilena 1964-1973, Lom, Santiago de Chile.

Vilanau, Conrad (2006): "Historia conceptual e historia intelectual", ArsBrevis, $N^{\circ}$ 12, 151-164. Consultado el 11 de Junio, 2012. Disponible en: http://www.raco.cat/index.php/arsbrevis/article/viewFile/65855/76078

\section{Entrevistas}

Corvalán, Luis (2011) Entrevista realizada el Martes 19 de Julio de 2011. Moyano, Cristina (2011b) Entrevista realizada el Lunes 18 de Julio de 2011. 